Conclusion Despite numerous campaigns to improve patient involvement many still do not participate in their own safety. Patients without tertiary education, patients over 60, and those who are not fluent in English are much less willing to challenge healthcare professionals about safety-related issues. Understanding the impact of patient demographics on participation in safety behaviours could help to create novel, more targeted strategies to improve patient safety. This could effectively reduce preventable medical errors in palliative care medicine where patients are more vulnerable to such errors.

\section{EMPIRICAL ETHICS AND PALLIATIVE CARE: A SYSTEMATIC REVIEW OF THE ETHICAL CHALLENGES IDENTIFIED BY SPECIALIST PALLIATIVE CARE PRACTITIONERS IN THEIR DAY-TO-DAY CLINICAL PRACTICE}

Guy Schofield, Mariana Dittborn, Richard Huxtable, Emer Brangan, Lucy Selman. Univeristy of Bristol, King's College London, University of Bristol, The National Institute for Health Research Collaboration for Leadership in Applied Health Research and Care West (NIHR CLAHRC West) at University Hospitals Bristol NHS Foundation Trust

\subsection{6/bmispcare-2019-ASP.92}

Background Ethical issues arise daily in the delivery of palliative care. Despite much (largely theoretical) literature on the ethics of palliative care, evidence from specialist palliative care practitioners (SPCPs) about the day-to-day ethical challenges they encounter has not previously been synthesised. This evidence is crucial to inform education and training, and support staff.

Aim To synthesise the evidence regarding the ethical challenges which SPCPs of all professional backgrounds encounter during clinical practice.

Methods A prospectively registered systematic literature review using narrative synthesis methodology (Popay et al 2006) was conducted. Key words and subject headings of 8 databases (MEDLINE, Philosopher's Index, EMBASE, PsycINFO, LILACS, WHOLIS, Web of Science and CINAHL) were searched on $03 / 10 / 2018$, without time limits. Eligible papers reported original research using inductive methods to describe SPCP-reported ethical challenges, in any language. Quality was dual assessed using the Mixed-Methods Appraisal Tool. Tabulation, textural description, concept mapping and thematic analysis were used to develop and present the narrative.

Results 7040 records were screened. 12 studies from 9 countries were included. All included studies examined adult care. A broad range of ethical challenges were identified in 5 themes: patient-related (e.g. autonomy, truth-telling), patientfamily relationship (e.g. boundaries of confidentiality, familypatient conflict), clinical issues (e.g. futility, palliative sedation), organisational factors (e.g. value differences between professions and care settings, place of care), and wider system (e.g. euthanasia, organ donation).

Conclusion SPCPs encounter a broad range of ethical challenges, not all of which are recognised in the ethics literature or form part of training curricula. In particular, the challenges of differing value positions between hospice and curative sectors and genetics ethics seldom occur in theoretical discussions of palliative care ethics or training, while withdrawal of lifeprolonging treatment and euthanasia are more commonly represented. Findings of the review can inform SPCP ethics education, training and support.

\section{SYSTEMATIC REVIEW ON THE DOCTRINE OF DOUBLE EFFECT WITHIN PALLIATIVE CARE}

Craig Gannon. Princess Alice Hospice, Esher, Surrey, UK

\subsection{6/bmjspcare-2019-ASP.93}

Background The Doctrine of Double Effect (DDE) suggests pursuing a morally good action, despite foreseeable bad sideeffects (including death) is still ethical, providing the bad sideeffects weren't intended (within set circumstances). Consequently, DDE is a means of freeing doctors to prescribe morphine for pain at the end-of-life without misplaced legal fears. However, increasingly the role for DDE in Palliative Care is being questioned.

Our aim was to collate the current arguments for and against a role for DDE in Palliative Care, to provide an updated position.

Methods A systematic literature review was performed on DDE in Palliative Care. Peer-reviewed publications included if; English; abstract (to confirm applicability); from last 5 years (2013-2018). 10 full papers were analysed and key arguments summarised. This qualitative data was combined, addressing the research question.

Results Persuasive support both for and against DDE in Palliative Care was identified.

Positives; legal prerequisite (realising treatment morbidity/mortality); important moral 'tool' (doctors require 'good intentions'); and expert clinical support (championing DDE).

Negatives; unnecessary (no legal/clinical need); not applicable (distancing by palliative care); misinforms (fuels misplaced opioid fears); paternalistic (about staff, not patient-centred); unusable (complex, and intent/motive untestable); risks diversion from tailored dosing (poor practice, even if well-meaning); not a blanket 'doctrine' (or an 'untouchable' defence if misprescribe opioids).

Discussion The literature remains divided on current importance of DDE. DDE has inherent philosophical value with historical impact and current support. However, DDE's applicability in Palliative Care is unclear (because appropriate symptom control doesn't cause death); inconsistencies refute the presumed need (DDE is not needed to 'protect' prescribers in chemotherapy-related neutropenic sepsis deaths); and DDE allows potential harm (unintentionally providing a medical defence if deliberately administer a fatal opioid overdose)... sufficient to undermine DDE's current value. 'Best practice' appears a better tenet to guide doctors.

\section{LEAVING AN IMPLANTABLE CARDIOVERTER DEFIBRILLATOR ACTIVE AT END OF LIFE - BALANCING CURRENT AND POTENTIAL FUTURE HARMS}

Rosie Bronnert. University Hospitals of Leicester

\subsection{6/bmjspcare-2019-ASP.94}

The number of people with implantable cardioverter defibrillators (ICDs) has increased. Consequently more people approaching the end of their life have an ICD in situ.

Sensitive and timely conversations enable a planned ICD deactivation to take place in the majority of people approaching the end of their life. However, in a small number of cases, our multi-professional team have not been able to reach 
an agreed decision to deactivate the ICD with the patients/ their family.

In these situations, patients and families placed different weights to the clinical team on the benefits and harms of leaving the ICD active versus deactivated, often because of strong preferences or intrinsic values related to pursuing treatments.

National guidance exists about factors to consider when making decision about deactivation of an ICD at end-of-life. However, staff experienced conflict between their wish to deliver medically appropriate but personalised care.

The teams were fluently able to discuss the harms that can occur as a result of leaving an ICD active including the pain from shocks and distress witnessing this. However, further consideration of real-time harms that were occurring as a result of deactivation discussions was crucial to reaching a shared decision to leave these ICDs active, unless preferences changed or the ICD fired causing distress.

The particular harms included: deactivation becoming the focus of encounters rather than other issues such as symptoms (often patient led); loss of trust in patient-clinician relationships because of (perceived) failure to recognise the importance of the individuals values/perspective; time taken for further discussions in context of time as a scarce resource/precious in end of life situations.

Our experiences and practice evolve with each case, but being mindful of current versus potential future harms, and articulating these, has been helpful in reaching shared agreed decisions to leave some ICDs active at end-of-life.

\section{ADVANCE CARE PLANNING: STAFF PERCEPTIONS OF PATIENTS RIGHTS, CHOICES AND PREFERENCES}

Matthew Doré, Phil Moore, Derek Willis. Severn Hospice

\subsection{6/bmjspcare-2019-ASP.95}

Background Advance care planning (ACP) is a process of formal decision making and documentation for future reference. For this to be communicated effectively nuances such as the difference between; 'Choice', 'Preference' and 'Rights' are paramount for decision making and understanding. This communication need has to be present on both sides of the consultation table.

Aim To explore the perception and understanding of the terms; 'Choice', Preference' and 'Rights' of the palliative care multidisciplinary team in relation to aspects of ACP.

Methodology An electronic survey completed by clinical staff within Severn Hospice over a week period.

Results There were 32 respondents from 8 different job roles. $69 \%$ (22) stated 'place of death' as a 'Preference' with $28 \%$ (9) stating it a 'Choice'. Exploring 'DNACPR' demonstrated; 'Choice' 39\% (12)/'Preference' 29\% (8)/'Right' 35\% (11). Decisions regarding 'refusing care' were mostly seen as a 'Right' $(62 \% \mathrm{n}=20)$ whereas 'requesting aspects of care' such as admission and medications were perceived as 'Choice' $(40 \% n=13)$ or 'Preference' $(37 \% n=12)$.

The qualitative aspect asked for perceived definitions of 'Choice', 'Preference' and 'Rights' of which we split into multiple themes. 'Choice' had a predominance of the themes of 'options' and 'information'. 'Preference' had predominant themes of 'options' and 'if possible'. Rights had a more legal focus/aspect.
Conclusion There's considerable heterogeneity in the understanding of the terms; 'Choice', Preference', and 'Rights', and even more so between the terms 'Choice' and 'Preference'. Given this is conducted upon hospice staff this gives a measure for concern as potentially conflicting messages and understanding could be communicated.

\section{DNACPR PRACTICE: HAS THE TRACEY JUDGEMENT MADE A DIFFERENCE?}

Natasha Freeman, Beverley Clarke, Michael Macfarlane, Derek Willis. West Midlands Collaboration Actioning Research in End of Life and Supportive Care

\subsection{6/bmjspcare-2019-ASP.96}

Background A study earlier this year ${ }^{1}$ suggested that the 2014 Court of Appeals decision (The Tracey Judgement) had led to Do Not Attempt Cardiopulmonary Resuscitation (DNACPR) decisions being discussed more frequently with patients and their families in the hospice setting but there was a lack of clarity on what physical or psychological harm these discussions could cause.

We aimed to survey current practice amongst non-palliative care doctors and Clinical Nurse Specialists (CNS) regarding making and communicating DNACPR decisions, the impact of the Tracey judgement on their practice and their interpretations of harm.

Method An online anonymous survey was distributed to GPs, Consultants and CNSs in the West Midlands.

Results 89 responses were received (68\% GPs, 24\% consultants, 7\% CNSs). 90\% reported making DNACPR decisions on a regular basis. Reasons for not making DNACPR decisions included lack of time (50\%), responsibility lying with others (26\%) and fear of medicolegal consequences (13\%). Barriers to communicating DNACPR decisions included mental capacity of the patient (76\%), fear of causing distress $(24 \%)$ and lack of time (21\%). 51\% of respondents were aware of the 2014 Tracey judgement and 24\% reported it had changed their practice. Common themes regarding harm included a physical aspect (26\%), harm to patients (23\%), psychological distress (18\%) and emotional impact (9\%).

Conclusions These results suggest there are significant barriers to making and communicating DNACPR decisions and a lack of awareness about the Tracey judgement amongst non-palliative care doctors. Although some common themes emerged regarding interpretations of harm, the variation within this group suggests individual beliefs and values may influence interpretation of harm.

\section{REFERENCE}

1. Macfarlane M, Shayler S, Nelms L, WM CARES Group, et al. Tracey judgement and hospice DNACPR orders: steady as she goes or seismic change? BMJ Supportive \& Palliative Care 25 July 2018. doi:10.1136/bmjspcare-2018-001518

\section{4 'IF I'M GOING TO DIE, I WANT TO DIE BY 4PM:' THE IMPACT OF A TREATMENT WITHDRAWAL SCENARIO ON A SPECIALIST PALLIATIVE CARE TEAM}

Rosie Bronnert, Kathryn Lockwood. University Hospitals of Leicester

10.1136/bmjspcare-2019-ASP.97

Distress occurred within the hospital Specialist Palliative Care Team (SPCT) following the withdrawal of high flow oxygen 